\title{
Addressing the Livelihood of Non-Resettlers in Dam-Induced "Detached" Areas: The Case of the Shichikashuku Dam
}

\author{
Mikiyasu Nakayama (Corresponding author) \\ Graduate School of Frontier Sciences, The University of Tokyo \\ 5-1-5 Kashiwano-ha, Kashiwa, Chiba 277-8563, Japan \\ Tel: 81-4-7136-4869Ｅ-mail: nakayama@k.u-tokyo.ac.jp
}

Ryo Fujikura

Faculty of Sustainability Studies, Hosei University, Japan

E-mail: Fujikura@hosei.ac.jp

Received: February 1, 2019 Accepted: February 11, 2019 Published: February 28, 2019

doi:10.5296/jad.v5i1.14423 URL: https://doi.org/10.5296/jad.v5i1.14423

\begin{abstract}
Most dam construction projects inevitably lead to the creation of involuntary resettlers due to inundation of their lands and houses by reservoirs. How resettlers should be dealt with or "compensated" has long been discussed. The report published by the World Dam Commission was one of the major milestones on this issue. However, attention should also be given to the fact that non-resettlers who are obliged to stay in the project area after completion of a dam also suffer from dam construction. Even though their assets are not submerged, if their land is "detached" from the downstream area by a reservoir, they tend to become worse off socially and even financially. Improvement of infrastructure, in particular having roads to the downstream area, is essential to minimize the impacts on those who are "detached." Compensating for the lost assets of the resettlers alone may not be sufficient to prevent the people in the project area of a dam construction from becoming worse off.
\end{abstract}

Keywords: compensation, dam, Japan, livelihood, resettlement, Shichikashuku 


\section{Introduction}

Compensation for involuntary resettlers affected by dam construction projects has been a matter of social dispute, as well as academic research, for several decades in various parts of the world (Fujikura \& Nakayama, 2015). As a leading overseas development aid (ODA) institute which has funded numerous dam construction projects in the past, the World Bank has led the discussion on this issue since the late 1980s. In 1990, it issued a document titled "Operational Directive 4.30 - Involuntary Resettlement" - the first comprehensive guideline to better address the issue (World Bank, 1990).

The World Bank then initiated the establishment and operation of the World Commission on Dams (WCD). The WCD was supposed to function as an independent body "to develop decision-making criteria and policy and regulatory frameworks for assessing alternatives for energy and water resources development" and "to develop and promote internationally acceptable standards for the planning, assessment, design, construction, operation and monitoring of large dam projects" (IUCN \& World Bank, 1997, p. 10). In November 2000, the WCD published its only and final report, "Dams and Development" (WCD, 2000). How the guidance in this report should be regarded - namely whether it should be obeyed rigidly by funding organizations or not-provoked disputes between pro-dam and anti-dam organizations (Fujikura \& Nakayama, 2003). Nonetheless, publication of the report by the WCD should be regarded as a milestone, for it promoted discussions among an unprecedented number of organizations and individuals about dam construction, and in particular, about how the resettlers should be compensated.

Through these efforts, mostly made by the World Bank, the approach to dealing with involuntary resettlers has been refined in the last three decades. It should, however, be noted that dam construction creates difficulties not only for involuntary resettlers but also for non-resettlers. Non-resettlers in this study denote those who live in the same area as involuntary resettlers, but whose assets are not directly affected by dam construction (e.g., their land is located above the water level of the reservoir). In principle, compensation is given for assets lost due to dam construction. Resettlers lose their assets entirely or partly and they receive compensation in accordance with what they lose. Some non-resettlers lose a part of their assets; for example, a person's farmland may be above the water level while his house is to be submerged (which is entitled for compensation). Still, the majority of non-resettlers are not entitled to any compensation because their assets are not affected by dam construction.

If a village or town of non-resettlers is located downstream of the dam, their livelihood may not be greatly impacted because they will have the reservoir upstream from them. On the other hand, if they live in an area upstream of the reservoir, they may encounter difficulties. This is because their area would become physically and socially "detached" from areas downstream from the reservoir. Such an area may also lose societal connections to neighboring areas which are destined to be submerged by the reservoir. If a dam is built really deep in the mountains, there would be little chance that an area would be detached upstream of the reservoir. However, in a densely populated country such as Japan, building a dam and 


\section{Macrothink

subsequently creating a reservoir tends to create a detached area upstream. The livelihood of people who continue to live there after the emergence of the reservoir are negatively affected due to inevitable isolation from the downstream area. This study addresses the issue of the detached area and the livelihood of non-resettlers living there from the viewpoint of possible regulatory measures to mitigate difficulties they experience.

\section{Methodology and Case Description}

\subsection{Methodology}

The authors chose the Shichikashuku Dam in Tohoku, Japan, as the study case for this article. The details of the dam and history of its construction are described in the next section. In addition to literature surveys, in 2015 we visited the project command area of the Shichikashuku Dam, including the Shichikashuku Town government and the Shichikashuku Dam control station. We also conducted interviews in 2015 and 2016 in Shichikashuku with several first-generation resettlers and non-resettlers, under the condition that they remain anonymous.

\subsection{Chronology of Shichikashuku Dam Development}

The Shichikashuku Dam was constructed in the Miyagi Prefecture, Tohoku (North-Eastern in Japanese) region of Japan. The dam belongs to the Abukuma River basin, the second largest river basin in the Tohoku region after the Kitakami River basin. The dam, with a height of 93 meters and storage capacity of 109 million cubic meters, was constructed between 1983 and 1989. There had been 405 ha of land to be submerged, of which $17 \%$ were paddy fields, $13 \%$ were dry farmlands, and 56\% were forests (Saito, 1982). It commenced operation in 1991 as a multi-purpose dam, for the sake of flood control, irrigation, industry, and drinking water supply.

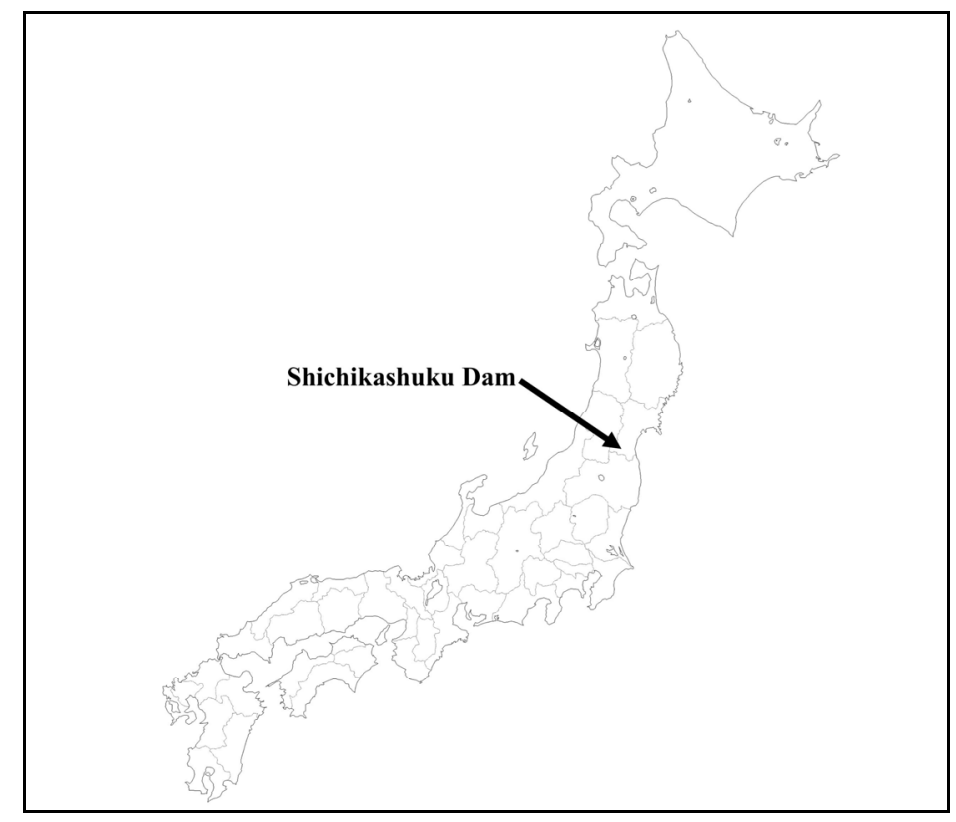

Figure 1. Location of the Shichikashuku Dam 
The former Ministry of Construction (which is presently the Ministry of Land, Infrastructure and Transport) initiated planning for the Shichikashuku Dam construction in 1971 and started detailed design in 1973. The citizens of (present) Shichikashuku strongly opposed its construction because 158 households with 640 people living in three major villages in the town would be obliged to resettle. These three villages to be submerged constituted the major part of Shichikashuku Town. The town had to be detached in the upstream areas of the reservoir after dam construction. Loss of fertile farmland in the lowland (to be submerged) and isolation of the town from downstream areas by the reservoir were among the major reasons that residents strongly objected to the dam project. The negotiation between the Ministry of Construction and the residents faced an impasse in the mid-1970s (Ministry of Construction, 1984).

The Ministry of Construction in 1978 then designated Shichikashuku Dam as eligible for article 9 of the Act on Special Measures for Reservoir Areas Development (ASMRAD, Suigen Chiiki Taisaku Tokubetsu Sochi Hou). The details of ASMRAD will be mentioned in the next section. This designation enabled the Ministry of Construction to offer a much more generous compensation package than before to both resettlers and Shichikashuku Town. Article 9 of ASMRAD is applicable to large dams. Once this article is applied, more funds are provided for some specific items such as road construction, farmland development, and flood control. The total cost of the Shichikashuku Dam development amounted to 53.5 billion Japanese yen (JICE, 1982). While the exact amount of funds provided by ASMRAD was not mentioned even in the detailed breakdown of the budget for the Shichikashuku Dam development and funding sources (JICE, 1982), MILT (2008) suggests that around 10 billion Japanese yen (approximately 90 million U.S. dollars per exchange rate in January 2019) of additional funds have been spent (on average) on a dam. It is safe to assume that additional funding in the amount of about $20 \%$ of the original budget was spent exclusively for resettlers and the project command area by ASMRAD in the case of the Shichikashuku Dam. As for the use of funds by ASMRAD in previous dam projects, approximately half of the additional funds (provided by ASMRAD) were spent for road works (Banba, 2004). Construction of high-quality roads was instrumental for development of the detached area to mitigate the impact of isolation from the downstream area. This was also the case with the Shichikashuku Dam.

The compensation package, which included additional measures provided by ASMRAD, proved instrumental towards finding agreement between the residents and the dam builder. Resettlers and the Ministry of Construction reached an agreement in August 1980 about the compensation package. The provision of compensation to resettlers started in November 1980. All the resettlers left their homes by March 1982. Out of 160 families to be resettled, only 19 families decided to move within Shichikashuku; the other families moved to the downstream areas such as the nearby major city of Shiroishi (Saito, 1982).

\subsection{Act on Special Measures for Reservoir Areas Development (ASMRAD)}

As Takahasi (2004) pointed out, compensation packages for large dam construction projects in Japan are currently usually composed of the following three pillars: (a) compensation for 


\section{MInstitute Macrothink $_{\text {Int }}$}

resettlers to be provided by the developer of the dam, (b) funds provided by ASMRAD for vitalization and anti-impoverishment initiatives in the project command area through infrastructure development (such as roads), industrial development, enhanced welfare for residents, measures for disaster prevention, improving the living environment, and promoting tourism by developing recreational facilities, and (c) sharing benefits of the dam construction between downstream and upstream areas by establishing a Fund for Reservoir Areas Development.

ASMRAD was established in 1973 by the Ministry of Construction to better address the financial needs of the project command areas of large-scale dam construction projects (Takahasi, 2009). ASMRAD aimed to mitigate the difficulties observed in negotiating with resettlers and others living in the project command areas of large-scale dam construction projects planned and implemented in Japan after World War II.

The Ministry of Construction had bitter experiences dealing with the issue of resettlement and compensation for troubled dam development projects in the 1950s, such as the infamous Shimouke Dam project (Takahasi, 2004; Nakayama, Takesada, \& Fujikura 2009). The Ministry of Construction thus established the "Guidelines for Compensation for Losses in Acquisition of Land for Public Use", adopted in 1962, and the "Guidelines for Public Compensation in Acquisition of Land for Public Use", established in 1966, as instruments to better address the resettlement issues created by dam construction (Takahasi, 2004).

However, these guidelines failed to meet the needs of resettlers and the non-resettlers in the project command area because (a) compensating resettlers for their land and assets was found to be insufficient to mitigate or resolve their worries about livelihood re-establishment after relocation and they were not satisfied with the resettlement packages offered (Note 1), (b) affected people in the project command area, both resettlers and non-resettlers, tended to regard themselves as victims of dam development projects, (c) difficulties with their future livelihood opportunities were anticipated by non-resettlers, in particular those in the "to be detached" areas, and (d) addressing the needs of resettlers and non-resettlers was often beyond the administrative capacity of local governments, particularly after completion of a dam, due to the shrinking and aging population of the remaining and often detached areas (Takahasi, 2004).

ASMRAD was designed to alleviate these problems that had been observed in past dam projects. The objectives of ASMRAD include improvement of "the stability and welfare of the residents" (Article 1) living in the reservoir areas. While 24 kinds of measures may be taken using the funds provided by ASMRAD, Table 1 shows 14 major measures for resettlers and non-resettlers in the project command areas which are made possible with the establishment of ASMRAD (Takahasi, 2004). Fixed property taxes may be reduced or exempted when the manufacturing or tourism industries expand facilities within the areas (Article 13). The national and local governments are also required to implement necessary measures other than those stipulated by ASMRAD for regional activation. 
Table 1. Major elements of activities supported by ASMRAD

\begin{aligned} & \hline 1 Land improvement. \\ & \hline 2 Erosion control. \\ & \hline 3 Development or improvement of roads. \\ & \hline 4 Development or improvement of water supply systems. \\ & \hline 5 Development or improvement of sewerage systems. \\ & \hline 6 Development or improvement of compulsory education facilities. \\ & \hline 7 Development or improvement of medical facilities. \\ & \hline 8 Residential site preparation. \\ & \hline 9 Development or improvement of public housing. \\ & \hline 10 Afforestation. \\ & \hline 11 $\begin{array}{l}\text { Development or improvement of joint-use facilities for the modernization of agriculture (including } \\ \text { livestock farming), forestry, and fishery management. }\end{array} \\ &$\hline 12 Development or improvement of public halls or other assembly facilities. \\ & \hline 13 Development or improvement of nurseries, children's community centers, or children's playgrounds. \\ & \hline 14 Development or improvement of regional welfare centers. \\ & \hline\end{aligned}

Source: (Takahasi, 2004).

\subsection{Reflections of First Generation Non-Resettlers and Findings from Site Visits}

In 2015 and 2016, the authors carried out interviews with several first generation resettlers and non-resettlers in Shichikashuku. It turned out that those resettlers who moved within the town (only 10 out of 158 families had to be relocated), but not to the downstream areas, had particular reasons for doing so, such as working as an officer in the Shichikashuku Town government.

One such resettler openly mentioned that he found the news of dam construction and his inevitable relocation as a great opportunity. This was because (a) he was not obliged to change his livelihood, for he decided to maintain his post in the town government after resettlement, (b) he had farmed as a side job despite farming being hard work and bringing only a small additional income, (c) he, thus, had no risk related to livelihood re-establishment associated with relocation, and (d) obtaining a great amount of money for his land that was to be submerged simply meant that he would become richer, and his old, worn house would be replaced with a new, modern residence. According to him, the majority of resettlers and non-resettlers actually recognized the dam construction as a good opportunity while both groups superficially opposed it to negotiate better compensation. He was, as a former staff member of the town government, very knowledgeable about ASMRAD. He found various measures taken using the funds provided by ASMRAD very useful for himself and the town. The roads were much improved after the dam construction, so that students in the town may 
now (i.e., after completion of the dam project) commute to a high school in the downstream area, which was not the case before. The town did not have a high school; therefore, students had to leave their homes and stay alone in a lodging facility in the downstream area, such as in Shiroishi City. The high school in Shiroishi is 25 kilometers away from the central part of Shichikashuku and it now takes only 40 to 50 minutes by bus thanks to the improved road.

A non-resettler interviewed also expressed his satisfaction about improved roads after dam construction. The road to Shiroishi was - thanks to many bridges built — fairly straight and driving to the downstream area did not pose any difficulty to the residents. It proved to be a great help for non-resettlers in the detached area who worked downstream because it reduced their daily commuting time.

Improved road traffic has led to the creation of a ski ground in Shichikashuku. However, it was not built with funds by ASMRAD, but with financial assistance from the (now defunct) Land Agency (Ando, 1989). Spending 1.2 billion Japanese yen for ski ground development was a big challenge for Shichikashuku, which had an annual budget of 1.36 billion Japanese yen for the 1983 fiscal year. The ski ground was inaugurated in December 1985 and it attracted 70,000 visitors in its first season in 1989 to 1990 (Ando, 1989). It also created additional part-time work for non-resettlers of the town in winter, when finding part-time jobs (such as roadwork) was difficult in the snowy area. This ski ground is still currently functioning and popular among skiers and snowboarders. Like other rural areas in Japan, Shichikashuku Town faces depopulation and aging. Its population decreased from 2,543 in 1985 (when the majority of resetters left the town) to 1,461 in 2015. However, it still attracted 500,000 visitors in 2016 (MILT, 2018).

\subsection{Comparison with the Case of the Sameura Dam in Kochi, Japan}

The Sameura Dam in the Yoshino River basin was built in 1975 in the Kochi Prefecture of the Shikoku region. Shikoku is one of the four major islands of Japan. Since the Shikoku region was less developed than mainland Japan in the 1950s, the Government of Japan established the Shikoku Region Development Promotion Act (Shikoku Chihou Kaihatsu Sokushin Hou) (Government of Japan, 1960) to promote economic development of the Shikoku region. Water resource development of the Yoshino River, the major river system of the region, was given high priority to serve as the engine for regional development. The Sameura Dam is a multi-purpose dam for irrigation, drinking and industrial water supply, flood control, and hydropower generation.

Parts of three local municipalities, namely Motoyama Town, Tosa Town, and Okawa Village, were destined to be submerged by the Sameura Dam construction. Among these municipalities, Okawa was most severely impacted (Matsumoto, Mizuno, \& Onagi, 2013). The major part of the village, including the building for the village government office, had to be submerged and 167 families had to be resettled. Because 141 families (out of the 167 that needed to be relocated) decided not to stay in the village but move to the downstream areas, Okawa suffered from a sharp decline in population (Okawa mura, 1981) — so much so that it has become the least populated village in Japan, except for villages on the small islands (Matsumoto, Mizuno, \& Onagi, 2013). 
One of the major reasons why Okawa suffered from such a rapid decrease in population was because the major part of the village became detached from the downstream area by the reservoir. New buildings for the village government office had to be developed in the detached area due to geographical constraints.

Okawa is not located in an isolated area. The distance from its village government office to the nearest motorway interchange is only 31 kilometers and it takes just 30 minutes from the interchange to Kochi City, the capital of Kochi Prefecture, to which Okawa belongs. The major obstacle is the road between Okawa and the downstream area; in this case, the road to the motorway interchange. The road twists and turns up the side of the mountain because few bridges were built to make the road straight. It signifies the difference from the case of Shichikashuku Dam, in which roads were well developed thanks to the funds provided by ASMRAD.

Such adverse impacts of the Sameura Dam construction were, in a sense, anticipated by those in Okawa before the commencement of dam development. At that time, the villagers requested a special subsidy for community rehabilitation that would include easy access to the downstream area. Okawa, however, failed to secure the requested subsidy to rehabilitate their livelihood because the Sameura Dam construction started before ASMRAD came into force in 1973. Consequently, only resettled individuals were compensated for their material loss and very limited funds were given for the livelihood of non-resettlers and the economic and social activities of the detached area (Matsumoto, Mizuno, \& Onagi, 2013).

The authors conducted interviews in 2011 with officials of the Okawa government under the condition that they should remain anonymous. They complained that they were deceived by the central government, saying that the central government must have been aware that ASMRAD was then under preparation and that it would be put into effect shortly. They blamed the central government, claiming it tried to "hide" ASMRAD (then under preparation) from their sight, so that the budget for the Sameura Dam construction would be minimized. The authors are not in a position to judge if their claim is valid or not, although their sentiments and anger for the lack of mitigation measures for the detached area was very vivid.

\section{Conclusion}

The case of the Shichikashuku Dam vividly illustrates that compensating for lost assets of resettlers alone may not be sufficient to prevent the project command area of a dam construction from becoming worse off. Detachment by reservoir from the downstream area results in various impacts for the livelihood of (mostly uncompensated) non-resettlers who stay in the detached area. The case of the Sameura Dam should be regarded as a typical failure because of the lack of support for the detached area.

ASMRAD had been applied to 97 dam development projects by 2018 (MILT, 2019). One of the most successful cases of regional activation is the Upstream Regional Stimulation Plan based on ASMRAD and adopted in 1997. It was formulated to develop the area surrounding the Miyagase Dam reservoir. The national government, the Kanagawa Prefecture government, 
and the Kanagawa Water Supply Authority jointly invested 67.9 billion Japanese yen and two parks were developed as one of the project components (Hattori \& Fujikura, 2009). As the area is located close to Tokyo and Yokohama, it attracts 1.6 million tourists annually (Prime Minister's Office, 2019). Tourism often plays a crucial role in the development of a local economy in reservoir areas, but substantial infrastructure investment is required.

It should be noted that the issue of non-resettlers and "detached areas" have not been adequately addressed by the dialogues in the global community about dam induced resettlement. The report by WCD (2000) did not touch on these issues. The authors stressed the importance of meeting the needs in the project command areas after completion of dams by showing the cases in Japan (Nakayama, Fujikura, \& Yoshida, 2002), while such an opinion is not yet prevailed in other countries.

Both the Shichikashuku and Miyagase cases demonstrate the effectiveness of ASMRAD for tourism development. Still, more post-project reviews should be carried out to determine if, and to what extent, ASMRAD functioned effectively for maintaining the livelihood of non-resettlers who were obliged to stay on in detached areas.

\section{Acknowledgments}

This work was supported by JSPS KAKENHI Grant Number JP16H03320. The authors appreciate the generous assistance of the Shichikashuku Town government in conducting the survey. The authors also thank the anonymous stakeholders who kindly responded to the interviews regarding the Shichikashuku Dam and Sameura Dam projects.

\section{References}

Ando, S. (1989). Shichikashuku machi no machi zukuri to damu heno kitai [Development of Shichikashuku town and prospect for dam]. Dam Nihon, Japan Dam Foundation, Tokyo, NO.540, 81-85.

Banba, T. (2004). Suigenchi Tokubetsu Sochi Hou to kono 30 nen [30 years after establishment of the Act on Special Measures for Reservoir Areas Development], Japan Dam Foundation, Tokyo. Retrieved on 26 January 2019 from http://damnet.or.jp/cgi-bin/binranB/TPage.cgi?id=77.

Fujikura, R., \& Nakayama, M. (2003). Perception gaps among stakeholders regarding the WCD guidelines. International Environmental Agreements, 3(1), 43-57.

Fujikura, R., \& Nakayama, M. (2015). Resettlement policy in large development projects. London: Routledge.

Government of Japan. (1960). Shikoku Chihou Kaihatsu Sokushin hou [Shikoku-Region Development Promotion Act], Government of Japan, Tokyo, Japan.

Hattori, A., \& Fujikura, R. (2009). Estimating the indirect costs of resettlement due to dam construction: A Japanese case study. International Journal of Water Resources Development, 25(3), 441-457. 
IUCN (World Conservation Union) and World Bank. (1997). Large dams: Learning from the past, Looking at the Future. Workshop Proceedings. IUCN, Gland, Switzerland and Cambridge, UK, and the World Bank, Washington, D.C.

JICE. (1982). Suigenchi Taisaku Binran [Manual on Measures for Headwater Area], Japan Institute of Country-ology and Engineering (JICE), Tokyo, Japan.

Matsumoto, K., Mizuno, Y., \& Onagi, E. (2013). The long-term implications of compensation schemes for community rehabilitation: The Kusaki and Sameura dam projects in Japan. International Journal of Water Resources Development, 29(1), 109-119.

MILT. (2018). Shichikashuku Damu Teiki Houkokusho [Periodical Report on Shichikashuku Dam], Tohoku Regional Development Bureau, MILT, Sendai, Japan, Retrieved on 1 February 2019 from http://www.thr.mlit.go.jp/bumon/b00037/k00290/river-hp/kasen/damukann/H29/kaigisiryou/0 2_H29sitikasyuku_houkoku.pdf.

MILT. (2018). Shitei Damutou Ichiran [List of Designated Dam and Lake], Ministry of Land, Infrastructure, Transport and Tourism (MILT), Tokyo, Japan. Retrieved on 1 February 2019 from http://www.mlit.go.jp/common/001053043.pdf.

Ministry of Construction. (1984). Shichikashuku Dam Hosho to Seikatsu Saiken [Compensation and Livelihood Re-Establishment of Shichikashuku Dam], Ministry of Construction, Tokyo.

Nakayama, M., Fujikura, R. \& Yoshida, T. (2002). Japanese experiences to enhance the World Commission on Dams guidelines, Hydrological Processes, 16, 2091-2098.

Nakayama, M., Takesada, N., \& Fujikura, R. (2009). Taking good care of project-affected families in dam construction projects. International Journal of Water Resources Development, 25(4), 629-639.

Okawa Mura [Okawa Village]. (1981). Okawa Mura Shiryou, Vol. 3 [Okawa Village document]. Kouchi-ken Tosa gun Okawa mura Komatsu Okawa Kyouiku Iinkai [Educational Board of Okawa Village], Okawa Village, Kochi, Japan.

Prime Minister's Office. (2019). Chiiki Saisei Keikaku, [Regional Reconstruction Plan], Prime Minister's Office, Tokyo, Japan. Retrieved on 1 February 2019 from http://www.kantei.go.jp/jp/singi/tiiki/tiikisaisei/dai41nintei/plan/y61.pdf.

Saito, K. (1982). Shichikashuku dam suibotsu hosho to suigenchi taisaku [Compensation and Measures for Headwater Area of Shichikashuku Dam], Dam Nihon, Japan Dam Foundation, Tokyo, NO.457, 31-41.

Takahasi, Y. (2004). Dams, environment and regional development in Japan. International Journal of Water Resources Development, 20(1), 35-45.

Takahasi, Y. (2009). History of water management in Japan from the end of World War II. Water Resources Development, 25(4), 547-553. 
WCD. (2000). Dams and development. Earthscan, London.

World Bank. (1990). Operational directive 4.30 - Involuntary resettlement. World Bank, Washington D.C.

\section{Note}

Note 1. Because compensation for a house is calculated by deducting depreciation from construction costs, it is not sufficient to build a new house equivalent to the original.

\section{Copyright Disclaimer}

Copyright for this article is retained by the author(s), with first publication rights granted to the journal.

This is an open-access article distributed under the terms and conditions of the Creative Commons Attribution license (http://creativecommons.org/licenses/by/4.0/). 